International Journal of Nursing

December 2017, Vol. 4, No. 2, pp. 80-89

ISSN 2373-7662 (Print) 2373-7670 (O nline)

Copyright (C) The Author(s). All Rights Reserved.

Published by American Research Institute for Policy D evelopment

D O I: $10.15640 /$ ijn.v4n2a7

URL: https:/ / doi.org/ D O I: 10.15640/ ijn.v4n2a7

\title{
Influencing Factors on Health-Promoting Lifestyle and Health Related Quality of Life among Adolescents: A Path Analysis Based on the Health Promotion Model
}

\author{
Mi-naJang ${ }^{1}$, 0 k kyungHam², HyunbongPark ${ }^{3}$, Hee soon Kim ${ }^{4}$
}

\begin{abstract}
The purpose of this study was to examine the direct and/ or indirect effects of individual characteristics and experiences, behavior-specific cognitions and affects, and interpersonal influences on health promotion behavior and health-related quality of life using the health promotion model. The study was performed with a cross-sectional design, and 346 students aged between 10 and 16 years voluntarily participated. The study instruments included Korean versions of the Self-Esteem Scale, the Multidimensional Scale of Perceived Social Support, the 21-item Depression Anxiety Stress Scales,the Strength and Difficulties Questionnaire, the Adolescent Lifestyle Q uestionnaire, and the Pediatrics Quality of Life Inventory TM 4.0. Data were analyzed using correlations and path analysis. The study identified significant direct effects of predictor variables (selfesteem, behavioral problems, and social support) on health promotion behavior. The study also found that emotional problems, behavioral problems, and health promotion behavior had significant direct effects on health-related quality of life $(\mathrm{p}<.05)$. By elucidating causal pathways, nurses could identify critical points for intervention that could enable the development of effective school health programs.
\end{abstract}

Keywords:quality of life, adolescent, self-efficacy, problem behavior, social support

\section{Factors Influencing Adolescents' H ealth Promotion Behavior and Health-Related Quality of Life}

Chronic disease is a serious health concern in Korea as well as in western countries, attributable to changes in lifestyle such as sedentary behavior and unbalanced diet (Park, 2014). Particularly, cerebrovascular disease and cancers are the major causes of mortality and morbidity, and are associated with unhealthy behaviors such as tobacco use, alcohol consumption, physical inactivity, and unbalanced diet (Kann, 2016).Because many of the health risk behaviors that contribute to these conditions begin and are reinforced during childhood, nurses working with children and families have a valuable opportunity to promote healthy lifestyles by providing school health programs (Kann, 2016; Lee \& Ham, 2013), which could affect youths' current as well as future health status (Sawyer et al., 2012).

Adolescence is a critical period in health promotion, as unhealthy behaviors have not yet been fixed. Physically, adolescents experience dramatic changes such as the manifestation of secondary sexual characteristics, yet, they are immature in biological, cognitive, emotional, and social aspects, and thus they are more likely to commit multiple risk behaviors (alcohol use, smoking, drug abuse, suicidal attempts, and violence) (Kim \& Kim, 2010; Y 00, 2009). Evidence also suggests that health risk behaviors increase significantly duning adolescence compared to childhood (Klosky et al., 2012; Sawye et al., 2012). Therefore, the prevention of health risk behaviors in the youth period is more effective than in adulthood and, accordingly, the importance of youth health promotion programs has been increasingly emphasized (Bandura, 2004, Ravens-Sieberer, 2008).

${ }^{1}$ D octoral student of College of Nursing, Y onsei University, Seoul, South Korea, College of Nursing

2D epartment of Nursing, Inha University, Incheon, South Korea

3 D octoral student of College of Nursing, Yonsei University, Seoul, South Korea, College of Nursing

${ }^{4}$ College of Nursing, Y onsei University, Seoul, South Korea, College of Nursing, Mo-im Kim Nursing Research Institute, Y onsei

University, Seoul, South Korea 
Adolescents in Korea experience severe academic stress because of the competitive college entrance process and academic achievement has always been a priority concern among them;thus,school health programs have been relatively less emphasized (Kim \&Lee, 2008). Former studies reported a high prevalence of lack of physical activity among youths, with $78 \%$ not performing regular physical activity, and a low proportion of participants having a balanced diet (Ministry of Education, Ministry of Health and Welfare, \& Centers for Disease Control and Prevention, 2015; Ministry of Health and Welfare \& Centers for Disease Control and Prevention, 2012). In addition, most adolescents die from suicide than any other diseases or accidents,which has doubled during the last decade in Korea (Shin et al., 2016).

In order to alleviate detrimental health problems, health promotion practices would be a cost-effective approach in the long-term (Abu-Moghli, Khalaf, \&Barghoti, 2010). Schools and families could collaborate in the implementation of health promotion school initiatives to help youths develop the health-related knowledge, values, attitudes, and skills that they need to make healthful lifestyle choices (Jang \& Kim, 2015; Thomas, McLellan,\&Perera, 2013).An understanding of the predisposing factors and determinants of health and health behavior should be preceded in order to develop effective health promotion programs(Kim \& Lee, 2008). Since the goal of health promotion is to achieve highest levels of well-being and health-related quality of life (HRQ oL), elucidation of the factors that influence HRQ oL is imperative(e.g., health promotion behavior) (Mohamadian et al., 2011). Some studies were conducted to identify the relationship between lifestyle behaviors (physical activity and eating behavior) and HRQ oL (Gopinath, Hardy, Baur, Burlutsky, \& Mitchell, 2012; Wu, O hinmaa, \&Veugelers, 2012). However, comprehensive approaches to understanding the roles of health promotion behaviors in relation toHRQ oL among youthshave been scarce, especially those applying a theoretical framework. Therefore, based on the health promotion model (Pender,1996), this study sought to understand the factors that predict health promotion behavior and HRQ oL among youths in order to provide baseline data for the development of school health programs.

\section{Conceptual Framework}

We applied theHealth Promotion Model (Pender, 1996) as a theoretical framework guide this study. This model identifies background factors that influence health behavior, and by using it, nurses can assist clients in modifying behaviors to achieve a healthful lifestyle and in turn promote HRQoL (Pender, 1996; Srof \& VelsorFriedrich, 2006). The components of the model include (a) individual characteristics and experiences, (b) behaviorspecific cognitions and affects, and (c) situational/ interpersonal influences (Pender, 1996).

Individual characteristics and experiences incorporate prior related behavior and personal factors that could not be modified through health promotion interventions (Srof \& Velsor-Friedrich, 2006). Our study included gender and school type(as personal factors), and experience of school health education(as a prior related behavior)as control variables. Perceived benefits and barriers, perceived self-efficacy, and activity-related affect were included as subcomponents of behavior-specific cognitions and affects. Former studies identified that mental health and conduct problems were significantly associated with health promotion behaviors (Adrian, Charlesworth-Attie, Vander Step, McCauley, \& Becker, 2014; Ravens-Sieberer et al., 2008); thus, in our study, instead of perceived benefits and barriers, we included emotional problems (depression, anxiety, and stress) and behavioral problems(hyperactivity/ inattention and peer problems) as components of behavior specific cognitions and affects.Some researchers have contended that self-efficacy and self-esteem are strongly related (Judge, Rrez, Bono, \&Thoresen, 2002), while others have shown that self-esteem significantly predicted health behaviors among university students (Mahmoodabad, Mehri, \& Morowatisharifabad, 2005).Self-esteem includes beliefs and feelings about oneself and implies self-evaluation, which is a crucial factor contributing to mental health as well as health and quality of life (Mann, Hosman, Schaalma, \& de Vries, 2004). Using the health promotion model, self-esteem was found to significantly influence perceived benefits and barriers, and was identified as a significant factor in emotional and behavioral problems (Lightsey, Burke, Ervin, Henderson, \& Yee, 2006; McCarroll, Lindsey, MacKinnon-Lewis, Chambers, \& Frabutt, 2009).

Therefore, as a predictor variable, self-esteem was included in the path model along with emotional and behavioral problems that determine health promotion behavior and HRQ oL in our study. Lastly, we included social support as an interpersonal influence variable, which was reported as a significant determinant of health promotion behaviors (Mohamadian et al., 2011; Kim \& Lee, 2008; Kim \& Kim, 2010). 
Applying the health promotion model, the purpose of this study was to examine direct and/ or indirect effects of individual characteristics (gender, school, and other control variables), behavior-specific cognitions and affects (emotional problems, behavioral problems, and self-esteem), and interpersonal influences (social support) on health promotion behavior and HRQ oL after controlling for personal factors (school type, gender, and experience of school health education) among youths in Korea.

\section{Method}

\section{Design}

O ur study employed a cross-sectional non-experimental design to describe the direct and indirect effects of self-esteem, behavioral problems, emotional problems, social support, and health promotion behavior on HRQ oL based on the health promotion model.

\section{Sample}

One elementary school in an urban area and one middle school in a metropolitan area agreed to participate in our study and helped to recruit study participants. Students from the fourth-to ninth-grades were recruited, whose parents as well as themselves could understand the purpose of the study and agreed to participate. According to the definition of adolescence, youths aged between 10-19 years were eligible to participate in our study (World Health O rganization (WHO), 2016). Based on the maximum likelihood estimation in structured equation modeling (SEM), a sample size between 150 and 400 was required (Hair, 2006); thus, we recruited 357 students. A total of 357 questionnaires were distributed, and after the exclusion of 8 questionnaires with incomplete answers, the questionnaires from 349 students were included in the analysis.

\section{Measures}

\section{General characteristics} education.

These variables included age, gender, school level (primary or secondary), and experience of school health

\section{Self-esteem}

The Self-Esteem Scale (Rosenberg,1965), which was translated into Korean by the Behavioral Science Research Center at Korea University (2000),was used to measure self-esteem after obtaining permission. This instrument includes ten items of positive (6) and negative (4) self-esteem questions and measured with a 4-point Likert scale. Higher total scores represent higher self-esteem. Cronbach's alpha was .75-.86 in a former study (Lee et al., 2009), and.86-.91 in the present study.

\section{Emotional problems}

The 21-item D epression Anxiety Stress Scale (DASS) was used to measure emotional problems (Lovibond \& Lovibond, 1995). We obtained permission from the authors of the original instrument, and we utilized a Korean version of the DASS (K-DASS-21). The instrument consists of 21items in three subscales: depression, anxiety, and stress. The depression scale assesses dysphoria, despair, worthlessness, and indifference. The anxiety scale measures transient anxiety and perception of anxious affect experiences. The stress scale examines difficulty in relaxation, nervous arousal, emotional restless, and intolerance (Lovibond \& Lovibond, 1995). Responses were measured with a 4-point Likert scale, with higher total scores represent worse depression, anxiety, and stress (range 0-63). Cronbach's alpha was .89-.91 in the former study (Lovibond \& Lovibond, 1995) and .79-.87 in the present study.

\section{Behavioral problems}

The Korean version of the Strength and Difficulties Questionnaire (SDQ) (Goodman, 1997), which was translated by Ahn et al. (2002) was used to measure behavioral problems (SDQ-Kr). It was translated and backtranslated by Korean researchers and its validity and reliability were verified by using it with Koreans (Ahn et al., 2002). The SD Q- Kr consists of 20 items in five domains including emotional disturbance (5 items), conduct behavior disorders (5 items), hyperactivity/ inattention (5 items), peer relationship difficulties (5 items), and socially desirable behaviors (5 items). In this study, we included three domains of behavioral problems (conduct behavior disorders, hyperactivity/ inattention, and peer relationship difficulties) in the analysis. 
Higher scores indicate worse behavior problems. Items were scored on a 3 -point scale $(0=$ not true, $1=$ somewhat true, and 2=certainly true). Cronbach's alpha was .82 in the previous study (Ahn et al., 2002) and .79 in our study.

\section{Social support}

The Multidimensional Scale of Perceived Social Support was used to assess social support (Zimet et al., 1988), which was translated into Korean by Kim and Lee (2011). The12 item-scale measures perceived support from significant others, friends, and members of a family using a 7-point Likert type scale (range 12-84). Higher scores indicate better social support perceptions. Cronbach's alpha was .85 in the original study (Zimet et al., 1988) and .96 in the present study.

\section{Health promotion behavior}

Health promotion behavior was assessed using the Adolescent Lifestyle Questionnaire (ALQ) (Gillis, 1997) after obtaining permission from the original author. The instrument consists of 43 items in seven subscales: life appreciation, healthy eating, engaging in physical activity, safety, health responsibility, social support, and stress management. Items are measured with a 6 -point Likert type scale $(1=$ never, $2=$ rarely, 3=sometimes, $4=0$ ften, $5=$ almost always), and the total score ranges between 43 and 215. Higher scores indicate positive health promotion behaviors. Cronbach's alpha was .91 in the former study (Gillis, 1997) and .95 in our study.

HRQoL. Assessment of HRQoL was performed with a Korean version of the Pediatrics Quality of Life Inventory (PedsQLTM 4.0) (Kook \& Varni, 2008) after obtaining permission from the original researchers. The instrument was developed by Varni, Seid, and Kurtin (2001) and consists of 23 items in four subscales including physical (8 items), emotional (5 items), social (5 items), and school functioning (5 items). It was measured with a 5point Likert scale $(0=$ never, $1=$ almost never, $2=$ sometimes, $3=$ often, and $4=$ almost always), and transformation of the scale items was performed $(0=100,1=75,2=50,3=25$, and $4=0)$. Higher scores indicate better HRQoL. Cronbach's alpha was .72-.87 in the former study (Kook \& Varni, 2008) and .91 in our study.

\section{Data Collection and E thical Considerations}

Data collection was conducted between October and November 2014 after obtaining approval from the Institutional Review Board of the university where authors are affiliated (IRB 2014-0037). School newsletters were sent to parents of potential participants, which informed the purpose of the study and incorporated consent forms. Returned signed consent forms were collected by the research assistants from the parents who agreed that their children could participate in our study. Before data collection, the research assistants also obtained verbal assent from the participating students whose parents had already submitted the signed consent forms. Upon completing the survey, US $\$ 3.00$ was offered to participating youths as a gift.

\section{Data Analysis}

Data were analyzed using SPSS WIN 21.0 and STATA/ IC 13.1. Descriptive statistics such as frequencies, percentages, means, and standard deviations was utilized to describe study variables. Pearson's correlation coefficients were used to identify correlations between the study variables. Path analysis was performed using a structural equation modeling (SEM) to explore effects of predictor variables on dependent variables. Maximum likelihood estimation was used (Kline, 2005), and significance test was performed using bootstrapping. Significance was determined at $\mathrm{p}<$ 0.05level.

\section{Results}

\section{Descriptive Statistics of General Characteristics and Study Variables}

Of the participating students, $50.9 \%(n=176)$ were male, while $49.1 \%(n=170)$ were female. The mean age (SD) was 12.95 (1.47) years, range:10-16 years. Primary school students constituted $48.8 \%$ ( $\mathrm{n}=169)$, and $51.2 \%$ $(n=177)$ were secondary school students. Sixty-two percent $(n=216)$ answered that they had experience of school health education. The mean score for self-esteem was 22.43 (5.47), range: 6-30;for emotional problems 7.87(9.38), range: 0-49;for behavioral problems 10.40(5.42), range: 0-29; and for social support 71.10(14.67), range: 12-84. The mean score for health promotion behavior was 160.99(29.35), range:67-215, and for HRQ oL 336.35(55.34), range: 70-400 (Table 1). 


\section{Comelation Matrix of Study Variables}

Significant positive relationships were identified between health promotion behavior, and self-esteem ( $\mathrm{r}=.663$, $\mathrm{p}<.001)$ and social support $(\mathrm{r}=.553, \mathrm{p}<.001)$, while significant negative association were found between health promotion behavior, and emotional problems $(r=-.451, p<.001)$ and behavioral problems $(r=-.512, p<.001)$. The results indicated that those with higher levels of self-esteem and social support engaged in better health promotion behavior than their counterparts. HRQ oL was positively correlated with self-esteem $(r=.569, p<.001)$, social support $(\mathrm{r}=.434, \mathrm{p}<.001)$, and health promotion behavior $(\mathrm{r}=.506, \mathrm{p}<.001)$, and negatively associated with emotional problems $(r=-.593, p<.001)$ and behavioral problems $(r=-.612, p<.001)$. These results suggest that high self-esteem, more social support, and better health promotion behavior lead to better HRQoL, while more emotional and behavioral problems are connected with worse HRQ oL (Table 2).

\section{Direct E ffect, Indirect Effect, and Total Effect on Health Promotion Behavior and Health-Related Quality of Life}

Path analysis was performed to determine the direct, indirect, and total effect of predictors on health promotion behavior and HRQ oL after controlling for personal variables (gender, school type, and experience of school health education) (Figure 2). Regarding the effects of the predictors on health promotion behavior, self-esteem had direct and indirect effects. Behavioral problems had a negative direct effect, while social support had a positive direct effect on health promotion behavior, after controlling for personal factors (gender, school type, and experience of school health education). Concerning Howl, the results indicated that emotional problems and behavioral problems had negative direct effects on HRQ oL, while health promotion behavior had a positive direct effect after controlling for personal factors. Social support had positive indirect effect on HRQ oL. The results indicated that health promotion behavior mediated the relationships between behavioral problems and $\mathrm{HRQ} \mathrm{oL}$, and between social support and HRQoL.

\section{Discussion}

Based on the health promotion model, this study performed path analysis to identify effects of predictor variables on health promotion behavior and HRQ oL among youths, and the results support the assumptions of the model. The study results reveal that self-esteem, behavioral problems, and social support had significant direct effects on health promotion behavior, while emotional problems, behavioral problems, and health promotion behavior had significant direct effects on HRQ oL. Behavioral problems and social support had indirect effects on HRQ oL. Health promotion behavior mediated the relationship between behavioral problems and HRQ oL, and between social support and HRQ $0 \mathrm{~L}$.

In our study, instead of perceived benefits and barriers, we included mental health (behavioral and emotional problems) in the model as a component of behavior-specific cognitions and affects. A former study conceptualized childhood psychopathology in two broad categories: internalizing problems(negative emotions), and externalizing problems (hostility, hyperactivity, and delinquency), and contended that both internalizing (emotional problems) and externalizing problems (behavioral problems)may co-exist upon emergence of precipitating factors in children and youths (Shaver, 2003).O thers have reported that mental health and conduct problems are significantly associated with health promotion behavior (Adrian et al., 2014; Ravens-Sieberer et al., 2008). Therefore, we were interested in whether these emotional and behavioral problems would have direct and/ or indirect effects on health promotion behavior and HRQ oL in children/ adolescents and we thus included them in the model.

Our study found that behavioral problems had a direct effect on health promotion behavior, while direct/indirect effects on HRQ oL. In this indirect effect, health promotion behavior mediated the relationship between behavioral problems and HRQoL. Similar to our study, former studies described that mental health was closely associated with health risk behavior (Patton et al., 2002). Especially, behavioral problems of mental health have a significant impact on health promotion behavior (Adrian et al., 2014). O thers also reported that HRQ oL was significantly different according to the behavioral problem scores using the SDQ (Ravens-Sieberer, Erhart, Gosch, Wille, \& European KID SCREEN Group, 2008). This study is unique in that we examined direct and indirect effects of mental health on health promotion behavior and HRQ oL among youths; associations between mental health and health promotion behavior had been previously analyzed among adults (Adrian et al., 2014). The current study found that the direct effect of emotional problems was not significant on health promotion behavior, but it was significant on HRQ oL. 
In line with our findings, former studies reported that more depressive symptoms and anxiety emotions have been associated with lower HRQoL (Stevanovic, D 2013), while lower levels of stress were associated with better HRQ oL (De Vibe, Bjømdal, Tipton, Hammerstrøm, \& Kowalski, 2012). Accordingly, the results of our study suggested that behavioral and emotional problems should be considered together in the development of interventions to improve HRQ oL in youths. Especially, interventions to modify behavioral problems would help to enhance both health promotion behavior and HRQ oL.

Schools could provide a positive environment to prevent mental health problems and school-based interventions could be effective in promoting socio-emotional competencies in children and adolescents, thereby decreasing the prevalence of mental health problems (Reinke, Stormont, Herman, Puri, \&G oel, 2011; Weare\&Nind, 2011). However, due to a lack of infrastructures and funds, mental health services in schools have been insufficient to deal with the mental health problems of high-risk groups. Thus, political and financial support is needed from the government to strengthen competencies of teachers in providing mental health services and to implement effective mental health programs in schools in partnership with local communities (Choi, 2012).

Our study found that social support had a positive direct effect on health promotion behavior, however, direct effect of social support on HRQ oL was not significant. Consistent with our study, former studies also reported significant direct effect of social support on health promotion behavior (Mohamadian et al., 2011; Kim \& Lee, 2008). An insignificant effect of social support on HRQ oL was also reported in other studies(Ravens-Sieberer, Erhart, Gosch, Wille, \& European KID SCREEN Group, 2008).However, our study found a positive indirect effect, and health promotion behavior mediated the relationship between social support and HRQ oL. The results of our study provide important implications for practitioners in that we found a significant association between social support and HRQ oL, while this relationship was mediated by health promotion behavior. The results suggest that provision of social support interventions will be more effective to improve health promotion behaviors and in turn promote HRQ oLthan those interventions directly provided to enhance HRQ oL.

Among adolescents, lower levels of connectedness to family, school, and teachers were found to be associated with increased health risk behaviors (Brooks, Magnusson, Spencer, \& Morgan, 2012; McNeely\&Falci, 2004). It was found that school connectedness was more influential in reducing health risk behaviors than family or teacher connectedness (Brooks et al., 2012). School connectedness includes liking school and a positive relationship with friends and teachers, and is associated with multiple health outcomes (Thompson, Iachan, Overpeck, Ross, \& Gross, 2006). During adolescence, emotional separation from parents is established, while peer influence becomes a dominant psychosocial issue. Thus, support form peers and teachers is important in preventing and avoiding health risk behaviors, while strategies to handle peer pressure will help adolescents to overcome barriers and make healthful lifestyle choices (Stang\& Story, 2005).

The study results revealed that self-esteem directly and indirectly influenced health promotion behavior, and social support had a positive direct effect on health promotion behavior, which is congruent with a previous study by Mann et al. (2004). O thers also investigated the direct path from self-esteem to health promotion behavior utilizing the health promotion model (Kim \& Lee, 2008; Pender, 1996).Positive self-esteem is considered as a protective factor against health risk behavior, and functions as an internal moderator in adverse situations, while social support could be used as an external moderator in such situations. Positive self-esteem is also associated with receiving respectful attention and affection (Mullis \& Chapman, 2000). Therefore, those with positive self-esteem would get more social support from peers and family members in implementation of health promotion behavior. Self-esteem also functions as a buffer in terms of adverse influence from others in relation to health risk behaviors (Mann et al., 2004; Mullis \& Chapman, 2000). Researchers have also contended that the sense of support from significant others (parents, teachers, and peers) is influential on the development of self-esteem. Therefore, strategies to enhance self-esteem in supportive social surroundings could be effective approaches to promote positive health behaviors among children and adolescents (Mann et al., 2004).In addition, offering school health programs focused on self-esteem building could yield multiple outcomes including academic achievement, positive social relations, reduced health risk behavior, and improved physical and mental health (King, Vidourek, Davis, \& McClellan, 2002; Mann et al., 2004).

The significant relationship between health promotion behavior and HRQ oL found in this study is consistent with previous studies (Mohamadian et al., 2011; Pender et al., 2010). The current study found that health promotion behavior not only directly influenced HRQ oL, but also mediated the relationship between predictor variables and HRQ oL. 
Health promotion behaviors such as non-smoking, physical activity, and balanced diet are well known to impact health positively, which in turn will enhance HRQ oL. Therefore, interventions to promote positive health behaviors would help to improve the HRQoL of youths (Mohamadian et al., 2011). The utility of the health promotion model was confirmed in our study in predicting health promotion behavior and HRQ oL, and found direct and indirect effects of multiple predictor variables among youths. The understanding of factors associated with health promotion behaviors should precede the development of interventions to promote positive health behaviors and HRQ oL. Accordingly, the results of our study provide valuable information for the planning of effective health promotion programs. The study results suggest that interventions to alleviate emotional and behavioral problems and efforts to enhance self-esteem along with social support services will help to increase health promotion behavior and HRQ oL among adolescents.

\section{Implications for School Nursing}

Schools can provide environments conductive to health education and health promotion programs to promote positive health behaviors and HRQ oL, which will contribute to the students' academic success and school completion (Committee for Education Funding, 2015; Lee, Lee, Cho, \& Park, 2009). Because many health behaviors begin and are reinforced during childhood, nurses in school settings have an opportunity to promote healthful lifestyles through school health programs (Lee \& Ham, 2012). School health programs can be one of the most costeffective investments to improve both health and education simultaneously (WHO , 2015). For effective school health programs, comprehensive approaches are needed to modify educational, social, economic, and political conditions to reduce risks associated with health and health behavior (WHO , 2015). By understanding the significant predictors and mediators influencing health promotion behavior and HRQ oL and elucidating the causal pathway from an independent to a dependent variable, nurses could identify critical points of interventions and thereby develop effective school health programs incorporating strategies to modify and/ or reinforce those critical components applying models of health behavior.

\section{Limitations and Recommendations for Future Research}

One of the study limitations may include use of the convenience sampling; thus, careful attention should be paid when generalizing our results. Furthermore, our study cannot exclude social desirability bias in some of the questions because data were gathered using a self-report method. Additionally, care should be taken in interpretation of the study results, since we did not include some of the health promotion model components in our study. Future studies are needed to include the variables of the health promotion model that were not considered in our study (i.e., perceived benefits and barriers, and self-efficacy), and investigate whether these variables significantly predict health promotion behavior and HRQ oL, and/ or they play a mediator or moderator role in explaining HRQ oL.

\section{Acknowledgements}

This research was funded by grants from Mo-im Kim Nursing Research Institute, Yonsei University

\section{Reference}

Abu-Moghli, F. A., K halaf, I. A., \&Barghoti, F. F. (2010).The influence of a health education programme on healthy lifestyles and practices among university students. International Journal of Nursing Practice, 16, 3542.http:/ / dx.doi.org/ 10.1111/ j.1440-172X .2009.01801.x

Adrian, M., Charlesworth-Attie, S., Vander Stoep, A., McCauley, E., \& Becker, L. (2014).Health promotion behaviors in adolescents: Prevalence and association with mental health status in a statewide sample.Journal of Behavioral Health Services and Research, 41, 140-152.http:/ / dx.doi.org/ 10.1007/ s11414-013-9370-y

Ahn JS, Jun SK, Han JK, Noh KS, \& G oodman R. (2003). The development of a Korean version of the strengths and difficulties questionnaire.Journal of Korean Neuropsychiatric Association, 42, 141-147.

Bandura, A. (2004). Health promotion by social cognitive means.Health Education \& Behavior, 31, 143-164. http:/ / dx.doi.org/ 10.1177/ 1090198104263660.

Behavioral Science Research Center Korea University (2000).Handbook of Psychological Scale II. Seoul, South Korea: Hakjisa

Boden, J. M., Fergusson, D. M., \&Horwood, L. J. (2008). D oes adolescent self-esteem predict later life outcomes? A test of the causal role of self-esteem. D evelopment and psychopathology, 20(1), 319-339. 
http:/ / dx.doi.org/ 10.1017/ S0954579408000151

Brooks, F. M., Magnusson, J., Spencer, N., \& Morgan, A. (2012). Adolescent multiple risk behaviour: an asset approach to the role of family, school and community. Journal of Public Health, 34, 48-56. http:/ / dx.doi.org/ 10.1093/ pubmed/ fds001.

Chen, X., Sekine, M., Hamanishi, S., Wang, H., Gaina, A., Yamagami, T., \&Kagamimori, S. (2005). Lifestyles and health-related quality of life in Japanese school children: a cross-sectional study. Preventive Medicine, 40, 668678. http:/ / dx.doi.org/ 10.1016/ j.ypmed.2004.09.034.

Choi, E. J. (2012). Policy development for adolescent mental health promotion.Health and Welfare Policy Forum, 188, 78-86.

Committee for Education Funding of USA. (2015). Education Matters: Invest in Learning for Health. Retrieved from http:/ / cef.org/ wp-content/ uploads/ 2015/ 04/ CEF-EdMattersHealth.pdf

De Vibe, M., Bjømdal, A., Tipton, E., Hammerstrøm, K. T., \& Kowalski, K. (2012). Mindfulness based stress reduction (MBSR) for improving health, quality of life, and social functioning in adults. Campbell Systematic Reviews, 8(3), 1-127. http:/ / dx.doi.org/ 10.4073/ csr.2012.3.

Gillis, A. (1997). The adolescent lifestyle questionnaire: development and psychometric testing.Canadian Journal of Nursing Research, 29, 29-46.

Goodman, R. (1997). The strengths and difficulties questionnaire: a research note.Journal of Child Psychology and Psychiatry, 38, 581-586. http:/ / dx.doi.org/ 10.1111/ j.1469-7610.1997.tb01545.x

Haavet, O. R., Saugstad, O. D ., \&Straand, J. (2005). Positive factors associated with promoting health in low-risk and high-risk populations of 15-and 16-year-old pupils in Oslo, Norway. ActaPaediatrica, 94, 345-351. http:/ / dx.doi.org/ 10.1111/ j.1651-2227.2005.tb03078.x

Hair, J.F. Jr., Black, W. C., Babin, B. J., Anderson, R.E., \& Tatham R. L. (2006). Multivariate data Analysis (6th ed.). Upper Saddle River, NJ: Pearson Prentice Hall.

Jang, B. S. \& Kim, D. H.(2015). Health literacy and health behavior in late school-age children.Journal of Korean Academy of Community Health Nursing, 26, 199-208. http:/ / dx.doi.org/ 10.12799/ jkachn.2015.26.3.199

Judge, T.A., Erez, A., Bono, J.E., \&Thoresen, C. J. (2002). Are measures of self-esteem, neuroticism, locus of control, and generalized self-efficacy indicators of a common core construct?Journal of Personality and Social Psychology, 83(3), 693-710.

Kann, L., McManus, T., Harris, W. A., Shanklin, S. L., Flint, K. H., Hawkins J.,...Zaza, S. (2016). Youth risk behavior surveillance-United States, 2015. MMWR. Surveillance Summaries, 65(6), 1-174. http:/ / dx.doi.org/ 10.15585/ mmwr.mm6523a7

Kim, H. K. \& Lee, M. H. (2011).Factors influencing resilience of adult children of alcoholics among college students.Journal of Korean Academy of Nursing, 41, 642-651. http:/ / dx.doi. org/ 10.4040/ jkan.2011.41.5.642

Kim, H. S., \& Kim, Y. I. (2010). Factors related to health promoting behavior in late school-age children. Journal of Korean Society of School Health, 23(1), 1-10. http:/ / dx.doi.org/ 10.12811/ kshsm.2013.7.1.045

Kim, K. Y., Park, S. W., Kim J. Y., Bae J., Lee, W. K., Jeong, S. H., ... Park, S. M.(2012). Trends in the prevalence of health risk behaviors among Korean adolescents, 2005-2009: The Korea Youth Risk Behavior web-based survey. Korean Journal of Health Education and Promotion, 29, 13-25.

Kim, S. H. \& Lee, J. H. (2008). Test of a Hypothetical Model for Health Promoting Behavior in School-aged Children. Child Health Nursing Research, 14, 22-34.

King, K. A., Vidourek, R. A., Davis, B., \& McClellan, W. (2002).Increasing self-esteem and school connectedness through a multidimensional mentoring program.Journal of School Health, 72, 294-299. http:/ / dx.doi.org/ 10.1111/ j.1746-1561.2002.tb01336.x

Kline R. B.(2005). Principles and Practice of Structural Equation Modeling, 2ND edn.Guilford press: New York.

Klosky, J. L., Howell, C. R., Li, Z., Foster, R. H., Mertens, A. C., Robison, L. L., \& Ness, K. K. (2012). Risky health behavior among adolescents in the childhood cancer survivor study cohort. Journal of Pediatric Psychology, 37, 634-646. http:/ / dx.doi.org/ 10.1093/ jpepsy/ jss046

Kook, S. H. \&Varni, J. W. (2008). Validation of the Korean version of the pediatric quality of life inventory 4.0 (PedsQL) generic core scales in school children and adolescents using the Rasch Model. Health Quality of Life Outcomes, 6, 41-55. http:/ / dx.doi. org/ 10.1186/ 1477-7525-6-41.

Lee, G.Y., \& Ham, O.K. (2012). Perception and needs in health education curriculum among school nurses as health teachers in Korea. Journal of School Nursing, 29(1), 10-18.http:/ / dx.doi.org/ 10.1177/ 1059840512449653 
Lee, Y. M., Schwarzer, R., \& Jerusalem, M. (1994).Korean adaptation of the general self-efficacy scale. Retrieved O ctober 2, 2007, from http:/ / userpage.fu-berlin.de/ health/ korean.htm

Lightsey Jr, O. R., Burke, M., Ervin, A., Henderson, D., \& Yee, C. (2006).Generalized self-efficacy, self-esteem, and negative affect.Canadian Journal of Behavioural Science, 38(1), 72. http:/ / dx.doi.org/ 10.1037/ h0087272

Lovibond, P. F., \&Lovibond, S. H. (1995).The structure of negative emotional states: Comparison of the Depression Anxiety Stress Scales (DASS) with the Beck Depression and Anxiety Inventories. Behaviour Research and Therapy, 33, 335-343. http:/ / dx.doi.org/ 10.1016/ 0005-7967(94)00075-U

Magalnick, H., \&Mazyck, D. (2008).Role of the school nurse in providing school health services.Pediatrics, 121, 10521056.http:/ / dx.doi.org/ 10.1542/ peds.2008-0382

Mahmoodabad, S.S.M., Mehri, A., \&Morowatisharifabad, M. (2005).The relationship of health behavior with selfesteem and self-efficacy in students of Yazd ShahidSadooghi University of Medical Sciences.Journal of Medical Education D evelopment Center,3(2), 111-117

Mann, M. M., Hosman, C. M., Schaalma, H. P., \& De Vries, N. K. (2004).Self-esteem in a broad-spectrum approach for mental health promotion.Health Education Research, 19, 357-372. http:/ / dx.doi.org/ 10.1093/ her/ cyg041

McCarroll, E. M., Lindsey, E. W., MacKinnon-Lewis, C., Chambers, J. C., \&Frabutt, J. M. (2009).Health status and peer relationships in early adolescence: The role of peer contact, self-esteem, and social anxiety. Journal of Child and Family Studies, 18(4), 473-485.http:/ / dx.doi.org/ 10.1007/ s10826-008-9251-9

McNeely, C., \&Falci, C. (2004).School connectedness and the transition into and out of Health-Risk behavior among adolescents: A comparison of social belonging and teacher support.Journal of School Health, 74, 284-292. http:/ / dx.doi.org/ 10.1111/ j.1746-1561.2004.tb08285.x

Melnyk, B. M., Small, L., Morrison-Beedy, D., Strasser, A., Spath, L., Kreipe, R., ...\& Van Blankenstein, S. (2006). Mental health correlates of healthy lifestyle attitudes, beliefs, choices, and behaviors in overweight adolescents. Journal of Pediatric Health Care, 20(6), 401-406.

Ministry of Education, Ministry of Health and Welfare, \& Centers for Disease Control and Prevention. (2015). The 11th Korea youth risk behavior web-based survey, 2015. Chungbuk, South Korea: Korea Centers for D isease Control and Prevention

Ministry of Health and Welfare, \& Centers for Disease Control and Prevention. (2012). Korean Community Health Survey, 2012.Seoul, South Korea: Ministry of Health and Welfare.

Mohamadian, H., Eftekhar, H., Rahimi, A., Mohamad, H. T., Shojaiezade, D., \&Montazeri, A. (2011).Predicting health-related quality of life by using a health promotion model among Iranian adolescent girls: A structural equation modeling approach.Nursing\& Health Sciences, 13, 141-148. http:// dx.doi.org/ 10.1111/j.14422018.2011.00591.X

Mullis, R. L., \& Chapman, P. (2000).Age, gender, and self-esteem differences in adolescent coping styles.The Journal of Social Psychology, 140, 539-541. . http:/ / dx.doi.org/ 10.1111/ 10.1080/ 00224540009600494

Kline R.B. (2005) Principles and Practice of Struc-tural Equation Modeling, 2nd edn.GuilfordPress, New York

Park, Y. H. (2014). Strategy for noncommunicable disease control and prevention.Journal of the Korean Medical Association, 57, 808-814. http:/ / dx.doi.org/ 10.5124/ jkma.2014.57.10.808

Patton, G.C., Coffey, C., Carlin, J.B., D egenhardt, L., Lynskey, M., Hall, W., 2002.Cannabis use and mental health in younger people: cohort study.British Medical Journal, 325, 1195-1198. . http:/ / dx.doi.org.ymlproxy.yonsei.ac.kr:8000/ 10.1136/ bmj.325.7374.1195

Puskar, K. R., \& Marie Bernardo, L. (2007). Mental health and academic achievement: Role of school nurses. Journal for Specialists in Pediatric Nursing, 12, 215-223. .

http:/ / dx.doi.org/ 10.1111/ 10.1111/ j.1744-6155.2007.00117.x

Ravens-Sieberer, U., Erhart, M., Gosch, A., Wille, N., \& European KID SCREEN Group.(2008). Mental health of children and adolescents in 12 European countries-results from the European KID SCREEN study.Clinical Psychology and Psychotherapy, 15, 154-163. . http:/ / dx.doi.org/ 10.1111/ 10.1002/ cpp.574

Ravens-Sieberer, U., Wille, D . P. N., Erhart, M., Bettge, S., Wittchen, H. U., Rothenberger, A.,...Barkmann, C. (2008). Prevalence of mental health problems among children and adolescents in Germany: results of the BELLA study within the National Health Interview and Examination Survey. European Child \& Adolescent Psychiatry, 17, 22-33. http:/ / dx.doi.org/ 10.1007/ s00787-008-1003-2 
Reinke, W. M., Stormont, M., Herman, K. C., Puri, R., \&Goel, N. (2011).Supporting children's mental health in schools: Teacher perceptions of needs, roles, and barriers.School Psychology Quarterly, 26(1), 1-13. http:/ / dx.doi.org/ 10.1037/ a0022714

Reuterswärd, M., \&Lagerström, M. (2010). The aspects school health nurses find important for successful health promotion. Scandinavian Journal of Caring Sciences, 24, 156-163. http://dx.doi.org/ 10.1111/j.14716712.2009.00699.x

Rosenberg, M. (1965).Society and the adolescent self-image. Princeton, NJ: Princeton University Press

Sawyer, S. M., Afifi, R. A., Bearinger, L. H., Blakemore, S. J., Dick, B., Ezeh, A. C., \& Patton, G. C. (2012). Adolescence: a foundation for future health.The Lancet, 379, 1630-1640. http:/ / dx.doi.org/ 10.1016/ S01406736(12)60072-5

Shin, H. Y., Lee, J. Y., Song, J., Lee, S., Lee, J., Lim, B., ... Huh, S.(2016). Cause-of-death statistics in the Republic of Korea, 2014.Journal of the Korean Medical, 59, 221-232.http:/ / dx.doi.org/ 10.5124/ jkma.2016.59.3.221

Shaver, A. E. (2003).Patterns of rule-violating behavior in children and adolescents.(Unpublished Doctoral Dissertation).The $\mathrm{O}$ hio State University, Columbus, $\mathrm{O}$ hio.

Shwarzer, R., \& Jerusalem, M. (1993).Generalized perceived self-efficacy scale. Retrieved October 2, 2007, from http:/ / web.fu-berlin.de/ gesund/ skalen/ Language_Selection/ Turkish

/ Ge neral Perceived Self-Efficac/ hauptteil general perceived selfefficac.htm Wallston, K. A.

Stang, J., \& Story, ${ }^{-}$M. (2005).Guidelines for adolescent nutrition services.Retrieved August 12, 2016 from http:/ / www.epi.umn.edu/ let/ pubs/ img/ adol ch1.pdf

Stevanovic, D. (2013). Impact of emotional and behavioral symptoms on quality of life in children and adolescents.Q uality of life Research, 22, 333-337. http:/ / dx.doi.org/ 10.1007/ s11136-012-0158-y

Thomas, R. E., McLellan, \&Perera, R.(2013). School-based programmes for preventing smoking. Evidence-Based Child Health: A Cochrane Review Journal, 8, 1616-2040. http:/ / dx.doi.org/ 10.1002/ ebch.1937

Thompson, D. R., Iachan, R., Overpeck, M., Ross, J. G., \& Gross, L. A. (2006).School connectedness in the health behavior in school-aged children study: the role of student, school, and school neighborhood characteristics.Journal of School Health, 76, 379-386. http:/ / dx.doi.org/ 10.1111/ j.1746-1561.2006.00129.x

Varni, J. W, Seid, M., \&Kurtin, P. S. (2001).PedsQL ${ }^{\text {тм }}$ 4.0: Reliability and validity of the Pediatric Quality of Life Inventory $^{\mathrm{TM}}$ Version $4.0 \mathrm{G}$ eneric Core Scales in healthy and patient populations.Medical Care, 39, 800-812.

Weare, K., \&Nind, M. (2011). Mental health promotion and problem prevention in schools: what does the evidence say? Health Promotion International, 26, 29-69. http:/ / dx.doi.org/ 10.1093/ heapro/ dar075

World Health O rganization (2016).School health and youth health promotion.Retrieved from http:/ / www.who.int/ school_youth_health/ en.

World Health Organization(2016). Ad̄olescent health.Retrieved fromhttp:/ / www.who.int/ topics/ adolescent_health / en/

Yoo, J. S. (2009). Factors influencing health risk behaviors in early adolescents. Journal of Korean Academic Community Health Nursing, 20, 296-306.

Zimet, G. D, Dahlem, N. W, Zimet, S. G, \& Farley, G. K(1988). The multidimensional scale of perceived social support.Journal of Personality Assessment, 52, 30-41. http:/ / dx.doi.org/ 10.1207/ s15327752jpa5201_2 